\title{
Landscape genetic approaches in conservation biology and management
}

\author{
Simone Sommer · Allan D. McDevitt • \\ Niko Balkenhol
}

Published online: 7 March 2013

(C) Springer Science+Business Media Dordrecht 2013

Landscape genetics is an integrative field of research that combines approaches from population genetics, landscape ecology, and spatial statistics (Manel et al. 2003; Storfer et al. 2007). It seeks to understand the influence of ecological and environmental constraints on genetic variation by quantifying the relationship between landscape features, genetic diversity and spatial genetic structure. The field is developing rapidly due to recent advances in molecular laboratory technologies, environmental data acquisition, and spatial analytical methods that can relate landscape and genetic data in meaningful ways (Storfer et al. 2010). The integrated approach allows an assessment of the impact of landscape composition, configuration, and matrix quality on the spatial distribution of neutral and adaptive genetic variation and associated microevolutionary processes across natural populations (Holderegger and Wagner 2008; Balkenhol et al. 2009; Manel et al. 2010; Segelbacher et al. 2010; Epperson et al. 2010). This understanding is crucial in order to promote research in evolutionary ecology and genetics, but also has tremendous potential for applied

S. Sommer $(\bowtie)$

Evolutionary Genetics, Leibniz-Institute for Zoo and Wildlife Research (IZW), Postfach, 601103 Berlin, Germany

e-mail: SOMMER@izw-berlin.de

\section{A. D. McDevitt}

School of Biology and Environmental Science, University College Dublin, Belfield, Dublin 4, Ireland

\author{
A. D. McDevitt \\ Mammal Research Institute, Polish Academy of Sciences, \\ Białowieża, Poland \\ N. Balkenhol \\ Department of Forest Zoology \& Forest Conservation, \\ Georg-August-University of Goettingen, Buesgenweg 3, \\ 37077 Goettingen, Germany
}

management and conservation of threatened or endangered plant and animal species (Sork and Waits 2010). It allows us to identify the effects of anthropogenic barriers that reduce gene flow or genetic diversity, and to predict the long-term effects of proposed management alternatives and specific reserve and corridor designs on genetic variation and population connectivity (Storfer et al. 2007).

This special issue includes 23 contributions spanning different aspects of landscape genetic research. It covers recent conceptual developments, study design and sampling considerations, and illustrates the usefulness and importance of integrated landscape genetic approaches in empirical applications to different taxonomic levels in plants, invertebrates and vertebrates.

\section{Conceptual framework of pattern-process relationships}

Understanding how landscape heterogeneity impacts gene flow and the spread of genetic variation is important for biological conservation given current global change (Segelbacher et al. 2010). However, the integration of population genetics, landscape ecology and spatial analysis remains an interdisciplinary challenge in terms of concepts and statistical methods. For example, there is no conceptual consensus on how to relate landscape and genetic data, and little is known about how variation in landscape pattern affects the detectability of landscape genetic relationships. Wagner and Fortin (this issue) present a conceptual framework to relate the spatial distribution of genetic variation to the processes of gene flow and adaptation as regulated by spatial heterogeneity of the environment, while explicitly considering the spatial and temporal dynamics of landscapes, organisms and their genes. Cushman et al. (this issue) use simulation modelling to 
quantify the effects of habitat area, fragmentation and the contrast in resistance between habitat and non-habitat on the apparent strength and statistical detectability of landscape genetic relationships.

\section{Study design and sampling}

An important research gap in landscape genetics is the impact of different field sampling designs and sampling effort on the ability to detect the effects of landscape pattern on gene flow. Oyler-McCance et al. (this issue) used a modelling approach to evaluate how different sampling regimes affect the probability of correctly identifying the landscape processes generating population structure. Naujokaitis-Lewis et al. (this issue) evaluated the usefulness of a network approach in landscape genetics to investigate the importance of sampling effort and topological network structure on estimates of genetic connectivity, and the role of landscape features on gene flow.

\section{Empirical application of landscape genetic approaches}

Gene flow, genetic diversity and differentiation

in spatially structured landscape

The stability and long-term survival of animal populations in heterogeneous landscapes largely depends on the ability to use and colonize habitat patches, as well as the exchange of individuals between patches. The degree of inter-patch dispersal, in turn, depends on the dispersal abilities of species and the landscape structure (i.e. the nature of the landscape matrix and habitat distribution). Anthropogenic habitat fragmentation may be detrimental for the long-term persistence of plant and animal populations, as it disrupts dispersal and gene flow, and undermines the balance between population extinction and colonization. Heidinger et al. (this issue) disentangled the effects of dispersal barriers and geographic distance on the genetic structure of bush cricket populations in a spatially structured landscape with patches of suitable habitat distributed within a diverse matrix of different habitat types. Hale et al. (this issue) studied the extent to which particular land-use practices disrupt dispersal and gene flow of an endangered frog species in an urbanizing landscape in southern Australia. Berkman et al. (this issue) investigated whether landscape resistance, geographic distance, or interstate highway barriers were related to the dispersal and gene flow of bobwhite. Miller et al. (this issue) determined the associations between forest fragmentation patterns and genetic structure of a globally endangered parakeet.
The relative influence on diversity pattern of historical biogeographical processes and recent human-induced population fragmentation is often difficult to disentangle. Ćosić et al. (this issue) assessed the impact of natural barriers, such as major rivers, and the level of recent anthropogenic habitat fragmentation on the genetic diversity and structure of European Ground Squirrel populations. Rather than analyzing genetic data from a single landscape, Balkenhol et al. (this issue) used a multiple landscape study design to compare genetic diversity and differentiation in a forest-specialist marsupial inhabiting fragmented forests in Brazil. Zielinski et al. (this issue) examine landscape effects on fine-scale population structure of a beaver species whose entire range is small but environmentally very heterogeneous, highlighting the importance of vegetation structure across small scales. Sotiropoulos et al. (this issue) examined the fine scale spatial genetic structure of two syntopic newts across a network of ponds. Fine-scale genetic population structure in relation to potential gene flow barriers was also investigated in chamois (Buzan et al., this issue) and wildcats (Hartmann et al. this issue). Atickem et al. (this issue) studied genetic population structure of the endangered Ethiopian mountain Nyala and used a network approach to recommend dispersal corridors for future conservation of this species.

Genetic population structure can also simply be a result of natural constraints of the habitat. Colson et al. (this issue) used a non-invasive approach to investigate the effects of watersheds as natural barriers on sex-specific dispersal at fine-scales in Sitka deer in Alaska. Coscia et al. (this issue) used genetic data and modelling by particle tracking to estimate the influence of ocean currents on larval transport of cockles.

Identifying genetic signatures of selection using a landscape genetic approach

Identifying the environmental factors potentially driving patterns of adaptive genetic variation offers a significant contribution towards conserving the evolutionary potential of organisms inhabiting heterogeneous landscapes. Congruent patterns among populations or species highlight the importance that landscape heterogeneity plays in determining genetic structure, whereas contrasting patterns emphasize differences in population- or species-specific ecology and life-history, or the importance of populationor species-specific adaptation to local environments. Bothwell et al. (this issue) identified genetic signatures of selection in a non-model plant species using a landscape genetic approach. Ackerman et al. (this issue) examined the interacting roles of demography and adaptation in determining spatial genetic structure in two closely related and 
geographically overlapping salmon species in a pristine environment.

Linking phenotype and environmental factors in complex landscapes

Only a few studies have considered both intrinsic (phenotype) and extrinsic (environmental) factors in understanding dispersal patterns and ultimately gene flow in complex landscapes. McDevitt et al. (this issue) investigated the relationship between dispersal, habitat selection and phenotype by examining the spatial ecology, body mass and fine-scale genetic structure of weasels. Bossart and Antwi (this issue) studied species-specific traits predicting genetic structure but not genetic diversity of three fragmented Afrotropical forest butterfly species.

Potential effects of future climate change on population connectivity and genetic diversity

Climate change is likely to alter population connectivity, particularly for species associated with higher elevation environments. Wasserman et al. (this issue) used different global warming scenarios to predict the potential effects of future climate change on population connectivity and genetic diversity in American marten to understand how connectivity among habitat patches will likely change (up until 2080), while providing an assessment of the simultaneous evolution of genetic diversity in this context. Ralston and Kirchman (this issue) applied GIS-based climate niche models to project geographic distributions of 15 boreal forest bird species for the year 2080 under two carbon emissions scenarios to predict the extent to which ranges will shift, and examined the potential effects of these shifts on the genetic diversity of the blackpoll warbler.

We hope that this special issue inspires collaborations integrating knowledge from various fields to further advance the growing field of landscape genetics. We thank the editor, Rus Hoelzel for inviting us as guest editors for this special issue. We would like to thank other associate editors who handled some of the included manuscripts. We are very grateful to all reviewers for their constructive comments. We appreciate the helpful and fast editorial support of the staff members of the Springer Journals' Editorial Office, Catherine Cotton, Gayathri Balasubramanian and Joy Pollin.

\section{References}

Balkenhol N, Gugerli F, Cushman SA, Waits L, Coulon A, Arntzen J, Holderegger R, Wagner HH (2009) Identifying future research needs in landscape genetics: where to from here? Landsc Ecol 24:455-463

Epperson BK, McRae B, Scribner K, Cushman SA, Rosenberg MS, Fortin M-J, James PMA, Murphy M, Manel S, Legendre P, Dale MRT (2010) Utility of computer simulations in landscape genetics. Mol Ecol 19:3540-3564

Holderegger R, Wagner HH (2008) Landscape genetics. Bioscience 58:199-207

Manel S, Schwartz MK, Luikart G, Taberlet P (2003) Landscape genetics: combining landscape ecology and population genetics. Trends Ecol Evol 18:189-197

Manel S, Joost S, Epperson BK, Holderegger R, Storfer A, Rosenberg MS, Scribner KT, Bonin A, Fortin MJ (2010) Perspectives on the use of landscape genetics to detect genetic adaptive variation in the field. Mol Ecol 19:3760-3772

Segelbacher G, Cushman SA, Epperson BK, Fortin M-J, Francois O, Hardy OJ, Holderegger R, Manel S (2010) Applications of landscape genetics in conservation biology: concepts and challenges. Conserv Genet 11:375-385

Sork VL, Waits L (2010) Contributions of landscape geneticsapproaches, insights and future potential. Mol Ecol 19:3489-3495

Storfer A, Murphy MA, Evans JS, Goldberg CS, Robinson S, Spear SF, Dezzani R, Delmelle E, Vierling L, Waits LP (2007) Putting the 'landscape' in landscape genetics. Heredity 98:128-142

Storfer A, Murphy MA, Spear SF, Holderegger R, Waits LP (2010) Landscape genetics: where are we now? Mol Ecol 19:3496-3514 